\title{
O pensamento de Antônio Gramsci como referencial teórico na pesquisa em história da Enfermagem
}

\section{The thought of Antonio Gramsci as a theoretical benchmark of study in the history of Nursing}

\section{El pensamiento de Antonio Gramsci como referencial teórico de estudios en historia de la Enfermería}

\author{
Miriam Heidemann', Maria da Luz Barbosa Gomes", Maritza Consuelo Ortiz Sanchez"I
}

\begin{abstract}
RESUMO
Cada pesquisador em história da enfermagem é livre nas suas interpretações. Todos nós sentimos necessidade de ordenar nosso campo teórico, para não cairmos no niilismo do caminhar desordenado pela história. Este artigo tem por objetivo propor uma reflexão teórica sobre o pensamento de Antônio Gramsci como referencial téorico de estudos em história da enfermagem. Para GRAMSCl, as relações de subordinação e dominação entre grupos são objetos da pesquisa histórico-social. A preocupação de Gramsci é o conjunto de forças que compõe a realidade e a relação entre essas forças, na busca pela hegemonia. A enfermagem representa uma força social, contruída por lutas e embates entre o poder político (dominante) e outros grupos sociais. A análise desses embates nos fornece focos de interpretação da história da enfermagem. A disputa pela hegemonia, num sentido amplo, sugere, através de revoluções passivas, alianças entre grupos, organização de associações de classe e sindicados, a construção de novos imaginários sociais, novas ideologias. A partir da lente gramsciniana de interpretação da história da enfermagem, podemos desenhar, através dos tempos, a identidade profissional do enfermeiro, que é o principal alicerce da conquista da hegemonia cultural da enfermagem.
\end{abstract}

Palavras chave: História; História da enfermagem; Pesquisa.

\section{ABSTRACT \\ Each history of nursing researcher is free in its interpretation. We all feel the need to order our theoretical field, not to fall in the nihilism of cluttered moving by history. This article aims to propose a theoretical reflection on the thought of Antonio Gramsci as a Theoretical benchmark of study in the history of nursing. To GRAMSCI, the relationship of subordination and}

domination between groups are objects of the social-history research. The concern of Gramsci is the set of forces that make up the reality and the relationship between these forces, in the quest for hegemony. Nursing represents a social force, created by fights and collisions between political power (dominant), and other social groups. The analysis of these collisions gives us outbreaks of the history of nursing interpretation. The dispute for hegemony, in a broad sense, suggests, through passive revolutions, alliances between groups, organization of trade unions and associations of classes, the construction of new social imaginary, new ideologies. From the lens of Gramsci interpretation of the history of nursing, we can draw, through the times, the identity of the nurse, which is the main basis of achievement of cultural hegemony of nursing.

Key words: History; Nurse history; Research.

\section{RESUMEN}

Cada investigador en historia de la enfermería es libre en sus interpretaciones. Todos nosotros sentimos la necesidad imperiosa de ordenar nuestro campo teórico, para no caer en el aniquilamiento del caminar desordenado por la historia. Este artículo tiene por objetivo proponer una reflexión teórica sobre el pensamiento de Antonio Gramsci como

Doutoranda em história da enfermagem pela Escola de Enfermagem Anna Neryda Universidade Federal do Rio de Janeiro (EEAN/UFRJ). Membro do Núcleo de Pesquisa de História da Enfermagem Brasileira (NUPHEBRAS) do Departamento de Enfermagem Fundamental (DEF/EEAN/UFRJ ). E-mail: miriam@fog.br.

"Doutora em Enfermagem pela EEAN/UFRJ. Professora Adjunto do DEF/EEAN/UFRJ . Pesquisadora do NUPHEBRAS/DEF/EEAN/UFRJ . E-mail marialuz@alternex.com.br.

III Doutora em Enfermagem pela EEAN/UFRJ. Pesquisadora do NUPHEBRAS/DEF/EEAN/UFRJ E-mail: morsa_peru@yahoo.com. 
Heidemann M, Gomes MLB, Sanchez COM. O pensamento de Antônio Gramsci como referencial teórico na pesquisa em História da Enfermagem. Rev. Eletr. Enf. [Internet]. 2008;10(4):1159-64. Available from: http://www.fen.ufg. br/revista/v10/n4/v10n4a29.htm.

referencial teórico de estudios en historia de la enfermería. Para GRAMSCl, las relaciones de subordinación y dominación entre grupos son objetos de investigación histórico-social. La enfermería representa una fuerza social, construida por luchas y embates entre el poder político (dominante) y otros grupos sociales. EI análisis de esos embates nos provee focos de interpretación de la historia de la enfermería. La disputa por la hegemonía, en el sentido más amplio, es hecha a través de revoluciones pasivas, alianzas entre grupos, organización de

\section{CONSI DERAÇÕES I NI CI AIS}

Cada pesquisador em história da enfermagem é livre nas suas interpretações. Mas todos nós sentimos necessidade de ordenar nosso campo teórico, para não cairmos no niilismo do caminhar desordenado pela história.

Precisamos interpretar a história da enfermagem com visões que se justificam a partir de determinadas abordagens teóricas. A partir da abordagem teórica escolhida reconstruímos o palco, o cenário, os atores da enfermagem, em um julgamento permanente, onde visualizamos vitórias, sucessos, fracassos, frustrações.

Esse julgamento sofre interferência de nossa visão de mundo, de nossa imagem do mundo da época, do nosso recorte temporal. Nossas conclusões constratam com nossas vivências e experiências que contextualizam e intertextualizam nosso momento histórico ${ }^{(1)}$.

A principal tarefa do historiador não é julgar, mas compreender. Entretanto, o que nos dificulta a compreensão não são apenas nossas convicções apaixonadas, mas também a experiência histórica que as formou ${ }^{(2)}$.

o campo teórico escolhido define a forma por que visualizamos a história da enfermagem. Podemos pensar num campo teórico de análise da história da enfermagem embasada na luta de classes, nas condições econômicas e materiais de uma sociedade, na sociologia das profissões, nas representações sociais de uma época, na violência simbólica, que constrói as relações sociais. Podemos definir nossa linha de pensamento como marxista, estruturalista, neopositivista, entre outras.

Este artigo tem por objetivo propor uma reflexão teórica sobre o pensamento de Antônio asociaciones de clase y sindicatos, la construcción de nuevos imaginarios sociales, nuevas ideologías. A partir de la óptica gramsciniana de interpretación de la historia de la enfermería, podemos diseñar, a través de los tiempos, la identidad profesional del enfermero, que es la principal base de la conquista de la hegemonía cultural de la enfermería.

Palabras clave: Historia; História de la enfermería; Pesquisa.

Gramsci como referencial téorico de estudos em história da enfermagem.

\section{NOTAS HISTÓRICAS SOBRE ANTÔNIO GRAMSCI}

Antonio Gramsci (Ales, 22 de janeiro de 1891 - Roma, 27 de abril de 1937) foi um político, filósofo e cientista político, comunista e anti-fascista italiano. Estudou literatura na Universidade de Turim, onde foi considerado um aluno brilhante ${ }^{(3)}$.

A cidade de Turim, à época, passava por um rápido processo de industrialização, com as fábricas da Fiat e Lancia que recrutavam trabalhadores de várias regiões mais pobres. Os sindicatos então se estabeleceram e começaram a surgir conflitos sociais motivados pelas relações trabalhistas. Gramsci envolveu-se diretamente com estes acontecimentos, frequentando círculos socialistas, bem como associando-se com emigrantes sardos ${ }^{(3)}$.

Gramsci, em Turim, tornou-se um notável jornalista. Apesar de sua fama, sua situação financeira não era boa. Suas dificuldades certamente moldaram sua visão do mundo e tiveram peso na sua decisão de filiar-se ao Partido Socialista Italiano(4).

Em 1924, Gramsci é eleito deputado pelo Veneto. Começa a organizar o lançamento do jornal oficial do partido, denominado L'Unità. Viveu em Roma, enquanto sua família permanecia em Moscou (esposa e dois filhos). Seus textos faziam duras críticas ao fascismo e ao Partido Socialista Russo(4).

Em 8 de novembro de 1926, a polícia fascista prendeu Gramsci. Ele foi sentenciado a 5 anos de confinamento (na remota ilha de Ustica); no ano seguinte ele foi condenado a 
Heidemann M, Gomes MLB, Sanchez COM. O pensamento de Antônio Gramsci como referencial teórico na pesquisa em História da Enfermagem. Rev. Eletr. Enf. [Internet]. 2008;10(4):1159-64. Available from: http://www.fen.ufg.br/revista/v10/n4/v10n4a29.htm.

vinte anos de prisão (em Turi, próximo de Bari, na Apúlia). Nesses vinte anos de encarceramento Gramsci escreveu as cartas do cárcere, onde concebe as bases de seu pensamento político ${ }^{(3)}$.

Em 1934 sua saúde estava seriamente abalada. Recebe a liberdade condicional. Falece aos 46 anos, pouco tempo depois de ter sido libertado(3).

\section{O PENSAMENTO DE ANTÔNIO GRAMSCI - A HEGEMONI A CULTURAL}

A base conceitual do pensamento deste autor é a hegemonia cultural. A hegemonia cultural é o meio de manipulação do estado capitalista $^{(5)}$.

A burguesia mantém o controle sobre toda a sociedade, não apenas através da coerção política ou econômica, porém também pela cooptação ideológica, por meio de uma cultura hegemônica na qual os seus valores e interesses particulares representam o "senso comum" da sociedade. Esse "senso comum" não como uma percepção empírica e passiva da realidade material, mas como uma construção mental realizada por todo indivíduo, grupo e classe, a partir das idéias recebidas ${ }^{(6)}$.

Nas sociedades ocidentais a hegemonia cultural provém principalmente da sociedade civil, através da formação e manutenção de aparelhos privados de hegemonia, como igrejas, escolas, universidades e associações, dentre outros ${ }^{(6)}$.

Para entendermos, em Gramsci, a construção mental do senso comum, da ideologia, precisamos analisar a idéia do imaginário socia ${ }^{(5)}$.

Através de nosso imaginário social apreendemos uma visão de mundo, (adquirimos uma Weltanschauung) como concepção ideológica, que nos leva a conhecer o real de determinado modo. Por meio da ideologia, que interpreta as relações sociais, o imaginário vai interferir na educação, na política, na economia, enfim, em toda a vida social.

A visão de mundo é constituída por um sistema de valores e de normas ligados às necessidades econômicas, sociais e políticas da sociedade $^{(7)}$.
Gramsci entende que a aceitação passiva da cultura, na instância preconceitual, fará com que se tome, como dogmas, as interpretações do imaginário social, que acabam por tornaremse objetivos de determinados grupos das sociedade ${ }^{(5)}$. A transmissão acrítica da cultura contribui para que preconceitos e fantasias sejam admitidos como válidos em um grupo cultural, e propagados às novas gerações como verdades indiscutíveis. São assim demarcados os papéis sociais e os ideais a serem alcançados.

A ideologia, em Gramsci, é a representação da realidade própria de um grupo social ${ }^{(5)}$. Para o autor citado, os sujeitos coletivos são definidos pelas ideologias.

Gramsci situa a hegemonia numa disputa no nível da superestrutura. A superestrutura dá sentido a duas idéias gramscianas: a idéia da sociedade política, que exerce a hegemonia através da coerção; e a idéia da sociedade civil (grupos sociais como associações, sindicatos), que formam alianças entre si em busca da hegemonia, da direção intelectual e moral ${ }^{(4)}$.

Hegemonia é o resultado do confronto de forças entre blocos sociais atuantes em determinado contexto histórico. É a capacidade de direção intelectual e moral, como política e cultura de uma classe ou grupo social sobre outra classe, grupos sociais ou frações de classe social.

$\mathrm{Na}$ nossa época, acentua-se o uso do termo hegemonia de classes, já com a possibilidade e mesmo com o imperativo da mutação do poder de uma classe para outra. Mais ainda: a supremacia não se restringe a uma ação político-militar, mas a outros fatores, como o econômico, o cultural e o religioso, que são elementos constitutivos a hegemonia ${ }^{(8)}$.

Em conformidade com esse pensamento, essa capacidade política traduz-se em um projeto, que se materializa por meio de determinada forma de direção, embasada em um estabelecimento de alianças. Em termos gerais, expressa os interesses, as reivindicações e a função histórica das classes subalternas, que sofrem diferentes influências ideológicas, impostas pelo ambiente em que estão inseridas $^{(6)}$. Essa concepção hegemônica guia as classes subalternas a assumir uma função 
Heidemann M, Gomes MLB, Sanchez COM. O pensamento de Antônio Gramsci como referencial teórico na pesquisa em História da Enfermagem. Rev. Eletr. Enf. [Internet]. 2008;10(4):1159-64. Available from: http://www.fen.ufg.br/revista/v10/n4/v10n4a29.htm.

dirigente. Portanto, capazes de construir, não só novas relações políticas e estatais, mas também uma nova cultura, uma nova visão de mundo.

\section{A APLICAÇÃO DO REFERENCIAL TEÓRICO GRAMSCIANO NA HISTÓRIA DA ENFERMAGEM}

A pesquisa histórico-social aponta a dinâmica do real na sociedade, esforça-se para entender 0 processo histórico em seu dinamismo, provisoriedade e transformação. Busca ainda apreender a prática social empírica dos indivíduos em sociedade (nos grupos e classes sociais), e realizar a crítica das ideologias, isto é, do imbricamento do sujeito e do objeto, ambos históricos e comprometidos com os interesses e lutas sociais de seu tempo ${ }^{(9)}$.

O histórico-social significa o estudo da concepção própria de mundo, do imaginário social de grupos sociais. As relações de subordinação e dominação entre grupos são objetos da pesquisa histórico-social ${ }^{(9)}$.

A preocupação de Gramsci é a realidade social. O conjunto de forças que compõe essa realidade e a relação entre essas forças.

A pesquisa em história é direcionada por uma intenção filosófica, o olhar o passado através de um ponto de vista particular ${ }^{(10)}$.

A enfermagem representa uma força social, contruída por lutas e embates entre o poder político (dominante) e outros grupos sociais. A análise desses embates nos fornece focos de interpretação da história da enfermagem.

Como no marxismo, Gramsci entende que a realidade material produz as condições de vida que expõe ao "homem" sua circunstância existencial. A partir dessa circunstância material partirão todas as suas idéias de mundo, ou seja, ideologias. Não é a idéia que produz a realidade, é a realidade que produz idéias. $E$ a pessoa é a idéia da personalidade sob forma coletiva.

Nesse sentido podemos concluir que o Estado, os grupos sociais, o sexo e a sociedade são culturalmente construídos ${ }^{(10)}$.

É importante referir que a concepção de Gramsci se faz a nível macro, de análise de um
Estado, e aponta caminhos para a supremacia do proletariado. Não faz parte de seu pensamento dividir o proletariado ou a burguesia em outras classes ou frações de classes sociais, ou mesmo classes profissionais. O que pretendemos neste artigo é apontar subsídios de aplicação das idéias macro em situações micro, representadas, neste texto, pelo grupo social da enfermagem em uma análise histórica.

A enfermagem apresenta várias faces nas relações de produção: o desenvolvimento de procedimentos curativos, preventivos, a habilidade na criação e utilização dos recursos tecnológicos, a sistematização da assistência de enfermagem, a qualidade e quantidade de serviços prestados à população, as atribuições estabelecidas ou a discussão sobre essas atribuições. Essas questões subentendem intenções de análise histórica baseadas em Gramsci.

A economia não é apenas a produção de bens materiais; é ao mesmo tempo produção das relações sociais dentro das quais essa produção se realiza ${ }^{(10)}$.

Toda e qualquer história pode ser analisada, interpretada, pela lente das relações sociais estabelecidas diante da produção de capital, numa linguagem marxista. $\mathrm{Na}$ linguagem gramsciana, essas relações significam embate de forças na busca pela hegemonia.

A história da enfermagem é uma história de conflitos, de embates, mais ou menos visíveis, numa disputa sobre as relações de poder. Esses embates estão na raiz das transformações sociais ${ }^{(11)}$.

A criação e manutenção das profissões estão inteiramente relacionadas com mecanismos de controle e de poder executados pelos interesses dominantes da sociedade ${ }^{(12)}$. $\mathrm{O}$ caráter subsidiário da enfermeira resulta do corolário de que o pensamento dominante em um determinado grupo profissional é pensamento do grupo aí dominante ${ }^{(13)}$.

O conceito de imaginário social pode ser a lente de entendimento da sociedade sobre o papel da enfermeira.

$\mathrm{Na}$ idéia do imaginário social podemos vislumbrar a identidade da enfermeira através 
Heidemann M, Gomes MLB, Sanchez COM. O pensamento de Antônio Gramsci como referencial teórico na pesquisa em História da Enfermagem. Rev. Eletr. Enf. [Internet]. 2008;10(4):1159-64. Available from: http://www.fen.ufg. br/revista/v10/n4/v10n4a29. htm.

dos tempos. Da enfermeira em seu perfil materno, serviçal, de branco nos hospitais, a pedir silêncio, da dama da lâmpada, nos ideais de Florence Nightingale, da heroína de guerra, no exemplo de Anna Nery, da religiosa em seu sacerdócio pela enfermagem, da profissão subalterna, da ocupação, da enfermeira sindicalizada, da enfermeira mulher, entre outros imaginários que podem ser trabalhados em uma pesquisa histórica.

A interpretação se fará mais plena quando - pesquisador relacionar a construção desse imaginário social da enfermeira em relação aos grupos hegemônicos da época pesquisada.

A história da criação e implantação de cursos auxiliares, técnicos e de graduação em enfermagem, nas várias localidades do país, pode ser analisada como uma resposta a necessidade do profissional de enfermagem para a garantia de hegemonia de determinados grupos sociais. A instalação de hospitais, clínicas, programas de saúde pública podem ser relacionados a estratégias de manutenção, bem como a renovação de hegemonias de grupo dominantes.

A questão da ideologia em Gramsci, a qual fundamenta análises históricas em enfermagem, oferece-nos dois prismas de interpretação:

1. a ideologia legitima um poder político dominante;

2. a ideologia se apresenta como um corpo de idéias característico de um determinado grupo ou classe social.

A única forma de o homem libertar-se das ideologias dominantes é partir da filiação ao partido comunista. Neste momento uma outra realidade, verdadeira, seria contruída e interpretada ${ }^{(4)}$.

Se aplicarmos esse conceito à enfermagem, podemos considerar que a enfermeira se libertaria dos ditames do imaginário social e da hegemonia dominante quando se organizasse em associações e sindicatos. A partir daí teria condições de, através de alianças com outras classes profissionais, ou organizações sociais, promover um embate pela hegemonia. O resultado seria a criação do bloco histórico da enfermagem que funcionaria como base de consentimento para uma determinada ordem social, uma nova ideologia, e promoveria a construção de um novo imaginário social.

No método dialético e na teoria política, quando o homem reconhece e organiza as forças sociais em força política, provoca sua verdadeira emancipação ${ }^{(14)}$.

Para Gramsci, a revolução é silenciosa, lenta, irreversível, através da construção de novos valores, ideologias e conseqüente transformação do imaginário social.

O pensamento de Gramsci sobre o intelectual orgânico, numa interpretação a nível micro, nos oferece duas possibilidades de análise da história da enfermagem.

Numa primeira análise, esse intelectual, enfermeiro, tal como o padre, o professor, o médico, representaria a manutenção e a reprodução dos valores da classe dominante sobre as classes subalternas.

Numa segunda análise, esse intelectual, político, é capaz de organizar entidades de classe, formar alianças e promover a construção de novos valores sociais e uma nova identidade profissional.

Portanto, a análise dos conflitos na disputa do poder, a própria profissão de enfermeiro e sua identidade social, a análise dos pensamentos hegemônicos de uma época e sua relação com a enfermagem, a enfermagem enquanto força produtora de capital, são interpretações possíveis na lente gramsciana.

\section{CONSI DERAÇÕES FI NAIS}

Como interpretamos em Gramsci, a hegemonia seria a destruição de valores sociais impostos pela classe dominante (hegemônica) e a contrução de valores mais justos, em busca de uma sociedade melhor. Nessa situação o enfermeiro seria o sujeito histórico. Aquele que desenvolve a filosofia da praxis, o fazer a história, e não apenas o analisar a sua situação histórica.

A riqueza de estudos em história da enfermagem se faz pelas várias interpretações que podemos dar a essa história. A própria escolha do objeto pode refletir a lente de interpretação da história. Consideramos uma atitude reducionista analisar recortes temporais ao utilizar sempre o mesmo referencial teórico. 
Heidemann M, Gomes MLB, Sanchez COM. O pensamento de Antônio Gramsci como referencial teórico na pesquisa em História da Enfermagem. Rev. Eletr. Enf. [Internet]. 2008;10(4):1159-64. Available from: http://www.fen.ufg. br/revista/v10/n4/v10n4a29.htm.

Seria trabalhar a verdade sob apenas um ponto de vista e uma visão de mundo. Não existe apenas uma história da enfermagem verdadeira e objetiva, mas, diferentes histórias e todas válidas.

O pesquisador de história que declara assumir um determinado referencial teórico deve estar ciente de que existem certas implicações. Coerentemente o pesquisador terá de partir de certos conceitos fundamentais do referencial e de uma certa visão da história para o caminhar de sua pesquisa(1).

As relações de forças de produção estão na busca da hegemonia de um grupo social sobre outro. Estabelecem-se, neste contexto, alianças, consensos, construção de novos valores sociais que se legitimam, na área do direito, em leis, códigos éticos, resoluções e pareceres.

Concluímos que o referencial teórico gramsciano nos permite uma interpretação estrutural da história da enfermagem imbricada nos comportamentos e embates dos grupos sociais.

A disputa pela hegemonia, num sentido amplo, sugere, através de revoluções passivas, alianças entre grupos, organização de associações de classe e sindicados, a construção de novos imaginários sociais, novas ideologias. Esses imaginários sociais e ideologias constróem a memória coletiva da enfermagem.

A partir da lente gramsciana de interpretação da história da enfermagem, podemos desenhar, através dos tempos, a identidade profissional do enfermeiro, que é o principal alicerce da conquista da hegemonia cultural da enfermagem.

\section{REFERÊNCI AS}

1. Barros JA. O projeto de pesquisa em história. Petrópolis: Vozes; 2005.

2. Barreira IA. Memória e história para uma nova visão da enfermagem no Brasil. Rev Latino-am Enfermagem. 1999; 7(3):87-93.

3. Japiassu H, Marcondes D. Dicionário Básico de Filosofia. 3rd ed. Rio de Janeiro: Zahar; 1996.

4. Gramsci A. Escritos políticos. Rio de Janeiro: Civilização Brasileira; 2004.
5. Gruppi L. O conceito de hegemonia em Gramsci. 2nd ed. Rio de Janeiro: Editora Graal; 1978.

6. Gramsci A. Cadernos do cárcere. Rio de Janeiro: Civilização Brasileira; 2004.

7. Minayo MC. O desafio do conhecimento: pesquisa qualitativa em saúde. São Paulo: HUCITEC/ABRASCO; 1994.

8. Sousa MSB. A formação do enfermeiro no Pará: passado e presente [thesis]. Rio de Janeiro: Escola de Enfermagem Anna Nery/UFRJ ; 1996.

9. Gramsci A. Concepção dialética da história. 4th ed. Rio de Janeiro: Civilização Brasileira; 1986.

10. Burke P. A escrita da história - novas perspectivas. São Paulo: UNESP; 1982.

11. Padilha MIS, Sobral VRS, Leite LMR, Peres MA, Araújo AC. A construção de um modelo de comportamento a partir dos discursos médicos do início do século. Rev Latino-am Enfermagem. 1997; 5(4): 25-33.

12. Meneses RMV. A formação da enfermeira no estado potiguar - da criação à consolidação [thesis]. Rio de Janeiro: Instituto de Medicina Social da Universidade do Estado do Rio de J aneiro; 2005.

13. Silva GB. Enfermagem profissional. São Paulo: Cortez; 1989.

14. Lowy M. Método dialético e teoria política. 4th ed. São Paulo: Paz e Terra; 1989.

Artigo recebido em 12.12.07.

Aprovado para publicação em 31.12.08. 